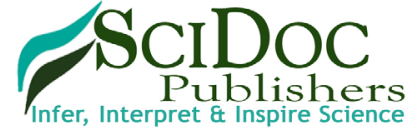

International Journal of Natural Disasters \& Health Security (IJNHS)

ISSN 2572-7540

\title{
Thermal Hot Spots in Cities as Hazards for Health Security: An Application for the Urban Agglomeration of Athens, Greece
}

\author{
Review Article
}

Cartalis $\mathrm{C}^{1^{*}}$, Santamouris, $\mathrm{M}^{1}$, Polydoros $\mathrm{A}^{1}$, Mavrakou $\mathrm{T}^{1}$

Department of Environmental Physics, National and Kapodistrian University of Athens, Athens, Greece.

\section{Abstract}

Urbanization affects dramatically the thermal environment of cities. The increase of impervious surfaces alongside with anthropogenic heat sources and the reduction of vegetated areas lead to elevated air and land surface temperatures and consequently to considerable public health risk. In this study a typology for thermal hot spots, that is areas in cities where higher than average land surface temperatures are consistently observed, is developed and applied - with the use of earth observation and ground data - for the city of Athens. Supervised classification is used to map the types of land cover in the study area, land surface temperatures are estimated using multi-seasonal satellite images (for specific synoptic conditions), and ground measurements of air temperature were used to establish a thorough understanding of the thermal environment. Results indicate that several hot spots exist (in some cases maximum surface temperatures exceeded $47^{\circ} \mathrm{C}$ in the summer months), especially in urban dense areas, the historic center of Athens and the industrial zone of the city. The recognition of thermal hot spots is important as they are practically urban hazards for health security, taken that they reflect areas where thermal comfort is reduced and photochemical air pollution is enhanced. Interventions in these areas are necessary for health security.

Keywords: Health Security; Thermal Hot Spots; Health Security; Cities; Hazards.

\section{Introduction}

The thermal environment is a significant part of the urban environment; it is a reflection of the surface and atmosphere energy balance as well as of the energy fluxes in between the surface and the atmosphere close to the surface. The state of the thermal environment may be described with the use of air temperatures (at $2 \mathrm{~m}$ from the ground) and land surface temperatures. The latter have a strong impact on the prevailing air temperatures locally, especially within urban areas.

Epidemiologic studies show that high temperatures are related to mortality and that older persons are especially susceptible to the adverse effects of heat [1-4]. In particular, heat-health relationships in urban areas have been studied extensively worldwide and these studies observed a U-, V- or J-shaped temperature-mortality relationship $[1-3,5,6]$. The adverse effect of extreme heat on mortality is exemplified by the 2003 European heat wave [7], when more than 70,000 additional deaths occurred.

The increasing urbanization of cities projected for the coming decades [8] is an important concern for health security, as air and surface temperatures are expected to increase further and the urban heat island strength to be intensified [9]. To this end, the analysis of the thermal environment in cities is important for building thermal resilience plans [10] for health security. Of particular concern are areas in the cities where higher than average (surface and air) temperatures are systematically observed. The recognition of such areas is important as they reflect areas where photochemical pollution may increase [11] and where immediate interventions are necessary to ameliorate the thermal environment and thus protect the health of the city dwellers. Furthermore quantifying the impact of heat on health security supports public health authorities for a coordinated heat response and in designing heat-resilient adaptations to housing and urban design.

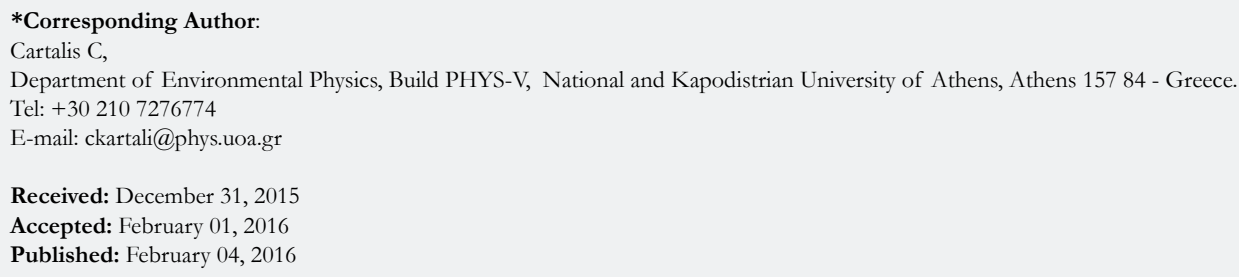

Copyright: Cartalis $\mathbf{C}^{\circ}$ 2016. This is an open-access article distributed under the terms of the Creative Commons Attribution License, which permits unrestricted use, distribution and reproduction in any medium, provided the original author and source are credited. 


\section{Methodology}

Land surface temperature (LST) is a key parameter for assessing the thermal environment in urban areas. Despite ground measurements, LST may be also estimated with the use of satellite data in the thermal infrared part of the electromagnetic spectrum [12-13], a fact which takes advantage of the high spatial resolution of the satellite sensor. In this study, the methodology to define hot spots in the city of Athens, is based on the use of Landsat 8 satellite images (of spatial resolution $120 \mathrm{~m}$ ) during summer, for days with similar synoptic conditions. The methodology observes the following steps:

Step 1. Classification of land cover for the greater Athens area in eleven classes (Figure 1). The classification is considered necessary so as to link LSTs with the type of land cover.

Step 2. Estimation of an average LST field for summer (Figure 2). LST values refer to the scale to the right of Figure 2, whereas air temperatures as measured at the ground based stations at the same acquisition time with the Landsat images, are presented as a second layer (black: urban; green: suburban; red: rural). For the estimation of the land surface temperature (LST) the algorithm (Eq.1) was used [14]. It is a generalized single-channel method in order to retrieve LST from only one thermal channel.
$\mathrm{LST}=\gamma\left[\varepsilon^{-1}\left(\psi_{1} \mathrm{~L}_{\mathrm{s}}+\psi_{2}\right)+\psi_{3}\right]+\delta(1)$

where Ls is the at-sensor radiance, $\varepsilon$ is the surface emissivity, $\gamma$ and $\delta$ are two parameters dependent on the Planck's function, $\psi 1$ is the reverse of the atmospheric transmissivity $(1 / \tau), \psi 2$ depends on the upwelling and downwelling atmospheric radiances and $\psi 3$ equals the downwelling atmospheric radiance.

Step 3. Estimation of LST zone statistics analysis (max, min and mean values) for the classes urban, suburban and industrial. As seen in Table 1, higher average LSTs are observed in the industrial and urban areas. It should be also noted that LSTs are considerable higher compared to air temperatures (on the average around 30 deg Celcius) at the same areas and observation times.

Step 4. Identification of hot spots in the city of Athens. The manual interpretation of the LST images, has showed that a local threshold of $44^{\circ} \mathrm{C}$ may be defined for the identification of hot spots. Thus an area with LST consistently above the threshold value is considered as urban hot spot. As expected hot spots are recognized in areas with such land cover as urban and industrial (Figures $3 \mathrm{a}$ and $3 \mathrm{~b}$ ). Vegetated areas such as urban parks are found with lower temperatures, although they are located near the aforementioned areas. Figure 4 provides a closer look to the areas concerned.

Figure 1. Classification of land cover for the greater Athens area.

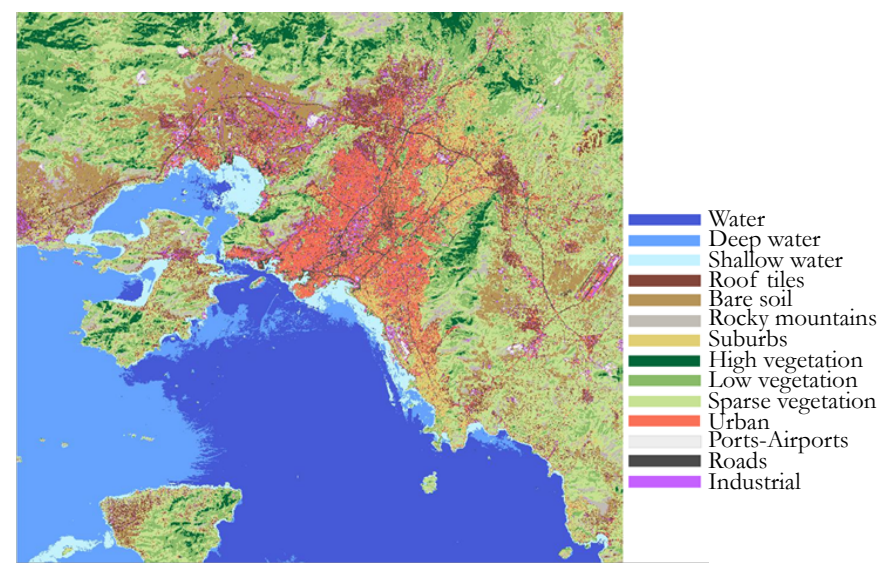

Figure 2. Estimation of an average LST field for summer for the urban agglomeration of Athens.

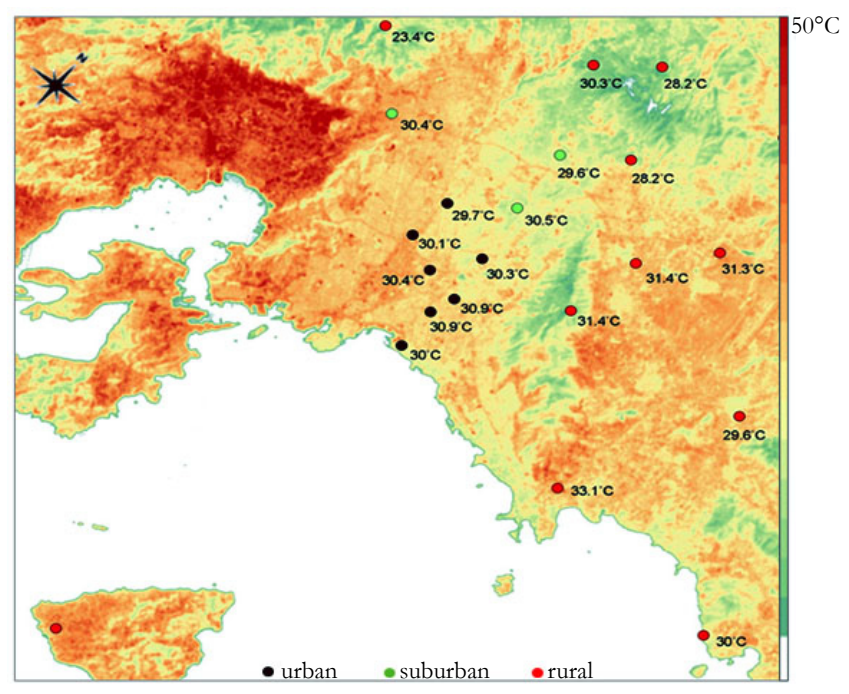


Table 1. LST zone statistics analysis.

\begin{tabular}{|c|c|c|c|}
\hline Area & LST $_{\min }$ & LST $_{\max }$ & LST $_{\text {average }}$ \\
\hline Urban & 25.1 & 46.8 & 38.9 \\
\hline Suburban & 24.6 & 45.3 & 37.1 \\
\hline Industrial & 25.1 & 47.7 & 40.0 \\
\hline
\end{tabular}

Figure 3a. The area of study is depicted in the rectangle.

Figure 3b. Identification of hot spots in the Athens historical centre and industrial zone. Colours correspond to the temperature scale to the left of the image.
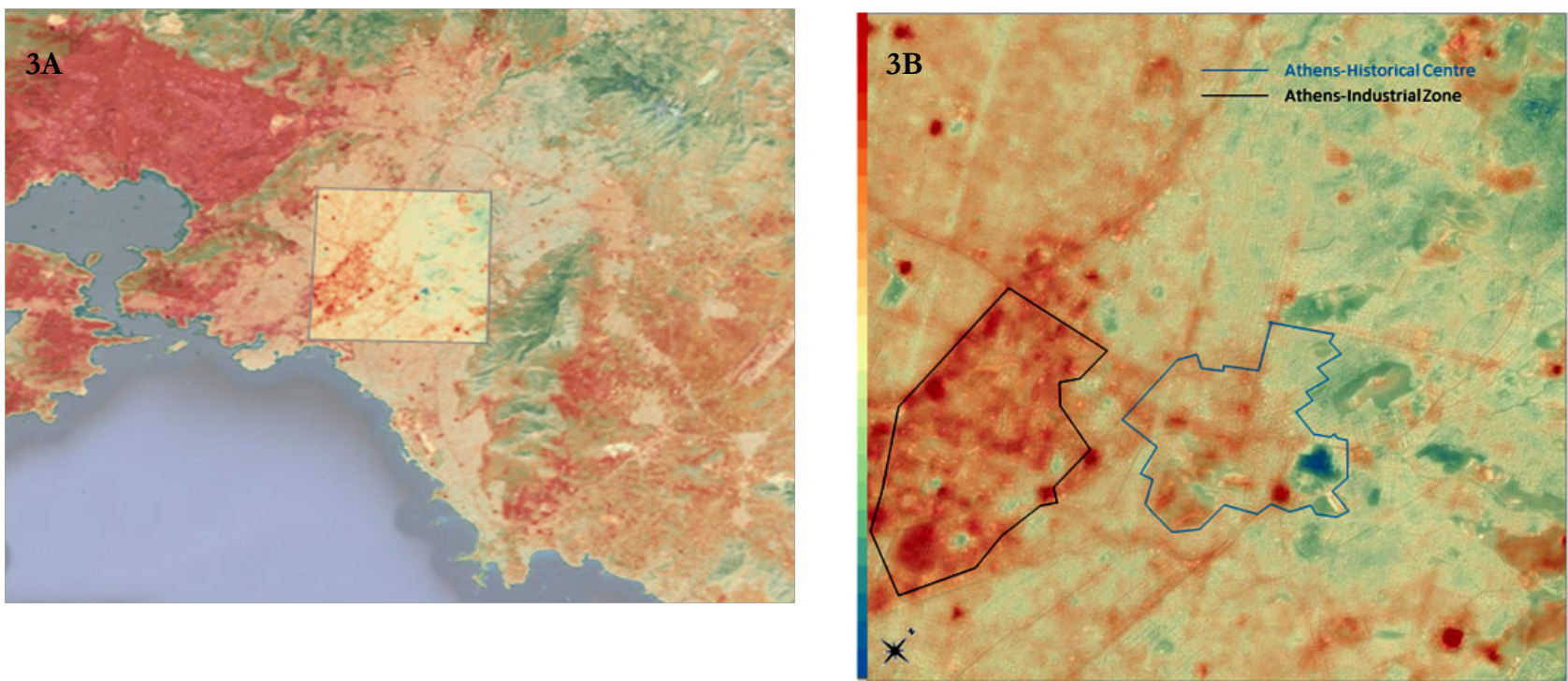

Figure 4. Close look of the urban areas related to hot spots.

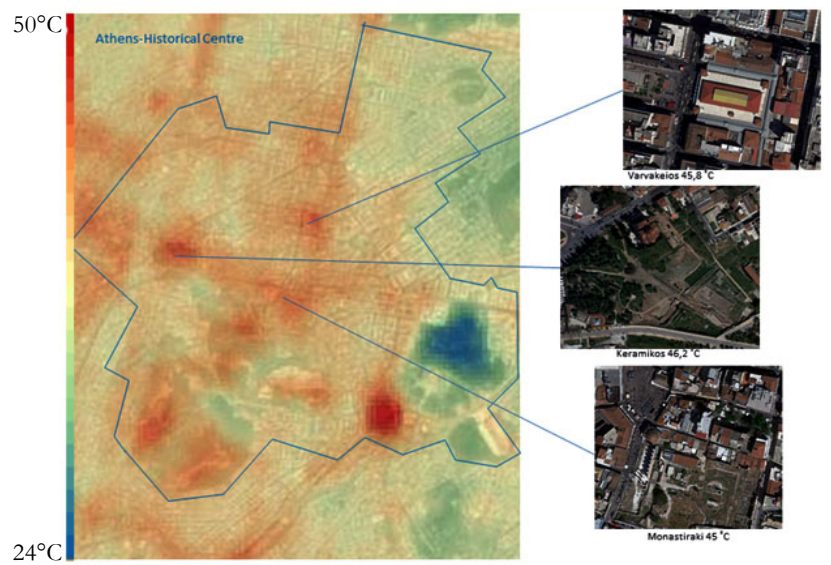

\section{Conclusions}

As seen in Figure 4 (a, b), several hot spots are identified within the city of Athens and particularly within the historical centre and the industrial zone of Athens. On the contrary, hot spots are not identified in the green areas of Athens and in the northern suburbs as LST is much lower. Results allow a detailed view of the thermal characteristics of an urban area (at a grid of $120 \mathrm{~m} \mathrm{x}$ $120 \mathrm{~m}$ ) in conjunction with the respective site-specific land cover types. To this end they (a) support the recognition of areas in the city where health security may be in pressure and (b) support the development of focused and differentiated interventions in the city so as to ameliorate heat stress in the areas where hot spots are identified and thus improve health security.

\section{References}

[1]. Katsouyanni K, Pantazopoulou A, Touloumi G, Tselepidaki I, Moustris K, et al. (1993) Evidence for Interaction between Air Pollution and High Temperature in the Causation of Excess Mortality. Arch Environ Health 48(4): 235-242.

[2]. Baccini M, Kosatsky T, Analitis A, Anderson HR, D’Ovidio M, et al. (2011) Impact of heat on mortality in 15 European cities: attributable deaths under different weather scenarios. J Epidemiol Community Health 65(1): 64-70.

[3]. D'Ippoliti D, Michelozzi P, Marino C, de'Donato F, Menne B, et al. (2010) The impact of heat waves on mortality in 9 European cities: results from the EuroHEAT project. Environ Health 9: 37.

[4]. WHO (2014) Ambient (outdoor) Air Quality and Health. http://www.who. int/mediacentre/factsheets/fs313/en/

[5]. Nicholls N, Skinner C, Loughnan M, Tapper N (2008) A simple heat alert system for Melbourne, Australia. Int J Biometeorol 52(5): 375-384.

[6]. Chan EYY, Goggins WB, Kim JJ, Griffiths SM (2012) A study of intracity 
variation of temperature-related mortality and socioeconomic status among the Chinese population in Hong Kong. J Epidemiol Community Health 66(4): 322-327.

[7]. Robine JM, Cheung SL, Le Roy S, Van Oyen H, Griffiths C, et al. (2008) Death toll exceeded 70,000 in Europe during the summer of 2003. C R Biol 331(2): 171-178

[8]. IPCC (2013) Climate Change 2013: The Physical Science Basis, Contribution of Working Group I to the Fifth Assessment Report of the Intergovernmental Panel on Climate Change. Cambridge University Press, Cambridge, USA. 1535.

[9]. Tam BY, Gough WA, Mohsin T (2015) The impact of urbanization and the urban heat island effect on day to day temperature variation. Urban Climate 12: $1-10$.
[10]. Cartalis C (2014) Towards Resilient Cities - A review of definitions, challenges and prospects. Adv Build Energy Res 8(2): 259-266.

[11]. Stathopoulou E, Mihalakakou G, Santamouris M, Bagiorgas HS (2008) On the Impact of Temperature on Tropospheric Ozone Concentration Levels in Urban Environments. J Earth Syst Sci 117(3): 227-236.

[12]. Stathopoulou M, Cartalis C (2007) Use of satellite remote sensing in support of urban heat island studies. Adv Build Energy Res 1(1): 203-212.

[13]. Voogt JA, Oke TR (2003) Thermal remote sensing of urban climates. Remote Sens Environ 86(3): 370-384.

[14]. Jiménez-Muñoz JC, Sobrino JA (2003) A generalized single-channel method for retrieving land surface temperature from remote sensing data. J GeophysRes 108(D22): 4688. 